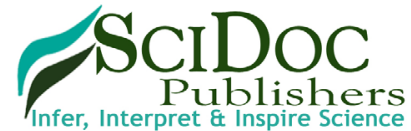

International Journal of Food Science, Nutrition and Dietetics (IJFS)

ISSN:2326-3350

\title{
Probiotics: A Way of Value Addition in Functional Food
}

\author{
Research Article
}

\author{
S. Sarkar ${ }^{1 *}$, A.Sur ${ }^{1}$, K. Sarkar ${ }^{1}$, R. Majhi ${ }^{1}$, S. Basu ${ }^{1}$, K. Chatterjee ${ }^{1}$, B. Sikder ${ }^{1}$
}

${ }^{1}$ Department of Quality Assurance Metro Dairy Limited Barrackpore-Barasat Link Road Subhasnagar, P.O. Neelgunj BazarKolkata-700121, West Bengal, India .

Abstract

An intense acceptance of functional foods due to consumer's demand, social attitudes, scientific evidence of the human health benefits of a particular ingredient coupled with commercially driven interest to add value to existing foods have projected probiotics as a new way in the current era of self-care and complementary medicine. Diverse functional properties of probiotics led their incorporation into conventional, dietary supplements and medicinal foods and must be ingested in sufficient quantities to exert health benefits but are often present at lower levels as per the label claims. Worldwide regulations related to probiotics are incoherent and adoption of assay techniques are inconsistent, therefore establishment and reinforcement of a quality assurance program to ensure "Standard of Identity" for adopting the label "Probiotic" is emerging.

\section{Introduction}

Fermentation employing lactic acid bacteria is the oldest, simple and safest means of food preservation. Fermentation of milk employing lactic acid bacteria induced an enhancement in its nutritional as well as therapeutic values. In recent years, with the realization of the link between diet and health, a worldwide consumer's inclination towards functional foods that possess certain health properties besides basic nutrition have been noted. Considerable efforts have been made to influence the intestinal microbiota by dietary means in such a way that the health of the host is beneficially affected. Functional properties of probiotics coupled with consumer's inclination towards healthful foods have projected probiotics as a new ingredient in functional food market. Probiotics may be defined as "live microbial food ingredient that, when ingested in sufficient quantities, exert health benefits on the consumer" [11]. Health benefits of probiotics led to a rapid growing interest in probiotics as functional foods in the current era of self-care and complementary medicine. It has been established that viability and metabolic activities of probiotics during food processing, at the point of sale and in host gastrointestinal tract are essential for extending health benefits. Several reports indicated poor viability of probiotics in health products and often present at levels lower than those claimed on label. For long-term existence of probiotic as functional foods in the world market, it becomes imperative to ensure their higher viability till consumption and ability to exhibit probiotic effect. The Food and Agriculture Organization of the United Nation's World Health Organization defines probiotics as live microorganisms which when administered in adequate amounts confer a health benefit on the host [14] and also laid down the Guidelines for the Evaluation of Probiotics in Food [15]. Implementation of a guideline for identification of a product containing probiotics as 'Probiotic' is emerging to build-up consumer's confidence and long-term sustainability of probiotic food industries.

\section{Colonization of the gut}

Development of a normal intestinal flora is a gradual and complex process and the colonic microbiota changes at different stages of life. At birth, the human gastrointestinal tract (GIT) is sterile and is subsequently colonized by mother's vaginal and faecal flora within hours [35]. In breast-fed infants Bifidobacterium bifidum accounts for $90-100 \%$ of intestinal microflora and dominates until 3 years of age [17]. Faecal bifidobacteria population $(\log \mathrm{cfu} / \mathrm{ml})$ elevated with increasing age (10-40 days) of infants from 9.199.61 to $10.67-11.04$ [31] but reduced to a level of 10.0 and fewer during weanling [26] and adulthood [9], respectively. Typical composition of intestinal flora is influenced by various factors such as

\footnotetext{
*Corresponding Author:

S. Sarkar

Department of Quality Assurance Metro Dairy Limited Barrackpore-Barasat Link Road Subhasnagar, P.O. Neelgunj BazarKolkata-700121, West Bengal, India.

E-mail: drsurajitsarkar@yahoo.co.in
}

Received: February 26, 2016

Accepted: April 20, 2016

Published: April 25, 2016

Citation: S. Sarkar, et al. (2016) Probiotics: A Way of Value Addition in Functional Food. Int J Food Sci Nutr Diet. 5(4), 290-293. doi: http://dx.doi.org/10.19070/2326-3350-1600052

Copyright: S. Sarkar ${ }^{*}$ 2016. This is an open-access article distributed under the terms of the Creative Commons Attribution License, which permits unrestricted use, distribution and reproduction in any medium, provided the original author and source are credited. 
age, nutritional requirements, susceptible to infection, immunological status of the host and the $\mathrm{pH}$, transit time, interactions between flora components, presence and availability of fermentable materials in the gut [7]. It has been established that an "optimum balance" between pathogenic and non- pathogenic bacteria in the GIT is of prime importance for maintaining good health and can be modulated by dietary interventions such as probiotics.

\section{Health beneficial targets of functional foods}

Most promising targets of functional foods are enumerated below:

- Intestinal function including those control transit time, bowel habits, mucosal motility and modulate epithelial cell proliferation

- GI function that are associated with a balanced colonic microflora, control of nutrient bioavailability, modify GI immune activity or that are mediated by the endocrine activity of the GI system

- Systemic function such as lipid homeostasis that are indirectly influenced by nutrient dosage or fermentation

Consumption of functional foods may extend the following health benefits to human beings:

- Reduced risk of cardiovascular disease

- Reduced risk of cancer

- Improved health in general

- Improved memory

- Improved weight loss/management

- $\quad$ Reduced risk of other diseases

- Reduced osteoporosis

- Improved mental health

- Quicker reaction time

- Improved fetal health

\section{Probiotics as a functional food}

Consumer's belief that certain foods can demonstrate potential health benefits has led to coin the term "functional foods", which are describe as nutrients that are separated from their established nutritional functions and some of these nutrients are proposed to promote GI mucosal integrity [12]. Probiotic organisms are capable of influencing the physiological and pathological process of the host by modifying the intestinal microbiota, thereby improving human health. Probiotics may be considered as a functional food for extending beneficial effects such as normalization of intestinal flora, anticarcinogenesis, hypocholesterolemic effect, alleviation of lactose malabsorption and alleviation of allergy. Beneficial health effects extend by probiotics is due to maintenance of the equilibrium of indigenous microbiota with the growth inhibition of pathogenic microorganisms and boosting of innate and acquired immunity. It was concluded that for probiotic products the zero risk does not exist as it may not have only positive effects but also some side effects, though the presently available products are excellent and further epidemiological and clinical studies are emerging for a proper monitoring of the consumer safety [25].

Probiotics proved to be efficacious in diverse health effects but further research is emerging to establish them and evaluate their safety as well as their nutritional aspects [22]. Majority of probiotics are generally regarded as safe (GRAS) but selecting and monitoring of probiotics are very important, when administered to patients with compromised immune systems, leaky gut or critical illnesses [16]. Focus was given on determining effective size, identifying responders and non-responders, clarifying strain-specificity of effects and confirming mechanisms mentioned for future dietary recommendations [14]. It was highlighted that probiotics can be dangerous, as they have been linked to an increase in mortality rate if administered to severely immuno compromised patients [4].

Specific health promoting activity of very few probiotics have been subjected to in vitro studies and even fewer have passed the appropriate human trials [6] and further the biological effects are strain specific and therefore general statement even for taxonomically closely related strains should not be made unless a common efficacy mechanism functions in both strains [33].

\section{Significance of viability of probiotics}

For exhibiting prophylactic properties, cultured milk products must retain sufficient population of viable organisms throughout its anticipated shelf-life. It was mentioned that the viability of microorganisms must be retained both at the end of incubation as well as at the date of expiry of the product [23]. The beneficial effect of probiotic intake is dose-dependent, a daily recommended dosage of $10^{6}-10^{9}$ viable organisms reaching the intestinal tract in humans being the most effective [18, 40, 20, 32, 10]. Ingestion of diverse cultured milk products containing $10^{7}-10^{9} \mathrm{cfu} / \mathrm{g}$ induce an elevation in faecal lactobacilli and bifidobacteria accompanied by a decline in coliforms and alleviated certain human diseases. Suggested daily intake being $>10^{8} / \mathrm{g}$ [29], probiotic products must be consumed regularly in sufficient quantities to deliver the relevant dosages of live bacteria to the gut[34] and the recommended intake is $300-400 \mathrm{~g} /$ week [39]. Based on clinical evidence, recommended dosage of probiotics to be $10^{8}-10^{10} \mathrm{cfu} /$ day for exhibition of health effects [28].

It is believed that probiotic viability is important to exhibit clinical effects but evidence indicated that dead or inactivated probiotic strains, or even their cellular components and culture broths can still have beneficial effects $[21,3,1]$. Cell wall components from both dead and living cells contributed to the probiotic efficacy [38] and removal of cholesterol from a medium by both nongrowing cells and dead cells of L. acidophilus was noted [24].

\section{Viability of probiotic in probiotic foods}

Survey reports on fermented functional foods and health-care products indicated either lower microbial content, present at a non-detectable level or the identified strains do not always correspond to those declared on the label. Assessment report on the probiotic food supplements, produced and distributed in the Italian market revealed non-conformance of $87 \%$ probiotic food supplements to the Italian guidelines in terms of both quantitative and qualitative due to poor quality control by manufacturers $[2]$.

A number of products bearing a label "probiotic" available in the market often do not meet minimum criteria for viable count at end of shelf life therefore, a recent panel of International Scientific Association of Probiotics and Prebiotics recommended that the term "probiotic" should be used only for products that deliver 
live microorganisms with a suitable viable count of well defined strains with a reasonable expectation of delivering benefits for the wellbeing of the host [19].

Bifidobacteria and Lactobacilli are also able to stimulate the development of the immune system, with certain species of gut commensal microbiota being required for immune regulation and tolerance of the large amount of antigens present in the gut $[36,41]$.

Initial concentration of yoghurt cultures must be maintained at 108-109 cells/ $\mathrm{ml}$ in milk [30] to compensate viability loss by heat, pressure, low water activity and high acidity [27] and for sustaining therapeutic dosage up to 21 days $/ 5^{\circ} \mathrm{C}$ (30). Viability of lactic acid bacteria is also reported to get influenced by gastric $\mathrm{pH}$, digestive enzymes, bile salts [8] and only $20-40 \%$ probiotic cultures survive the gastric transit (5). Exhibition of high resistance by Lactobacillus plantarum G1 and L. casei G3 to GIT environment such as low $\mathrm{pH}$ and bile salts and higher viability in the GIT of Wistar rats suggested their use as nutraceuticals or biotherapeuticals [42]. It is therefore necessary to ensure retention of viability of probiotic organisms both during processing, storage as well as transit through gastrointestinal tract with the objective of achieving prophylactic effects.

\section{Factors affecting viability of probiotics}

Following factors affect the viability of probiotics in yoghurt during manufacture, storage and gastrointestinal tract transit.

- Acid and hydrogen peroxide production by yoghurt cultures

- Dissolved oxygen content of the product

- Oxygen permeability through the package

- Concentration of lactic and acetic acids in the product

- Fat content of milk

- Heat-treatment of milk

- Incubation temperature

- Concentration of buffers such as whey protein concentrate

- Physiological status of probiotic cultures added

- Physical condition of product storage

- Possible interactions of the product with starter cultures

\section{Existing regulations for probiotics}

Presently, probiotic foods are not governed under specific European Union regulatory frameworks, however the Novel Food Regulation could be relevant in some special cases. European Food Safety Authority (EFSA) has launched the European Initiatives towards a "Qualified Presumption of Safety" (QPS) concept that allows strains with established extensive testing to enter into the market without extensive testing requirement.

Recent reports indicate two categories for "Food with Health Claims" in Japan namely "Food with Nutrient Function Claims" and "Food for Specified Health Uses" (FOSHU). For adopting the FOSHU label, the product must contain dietary ingredients that have beneficial effects on the physiological functions of the human body, maintain and promote health, and improve healthrelated conditions. However, claims of disease-risk reduction are not currently allowed under FOSHU.

In USA, Food and Drug Administration (FDA) have provided its "Partial List of Microorganisms and Microbial-Derived Ingre- dients that are used in Foods" which can be used as probiotics. Label of probiotic-containing food products declare the bacterial genera and species but not their levels of viable population. $\mathrm{Na}$ tional Yoghurt association (NYA) have allowed to use the "Live Active Culture Seal" for products containing $10^{8}$ viable cultures $/ \mathrm{g}$ at time of manufacture, however differentiate between lactic acid producing bacteria and probiotic bacteria or assurance of viability of cultures at end of shelf life are not furnished.

It can be observed that different countries across the world have diverse legislative view for probiotic containing foods, which causes difficulties for the consumers to decide or ensure whether they are getting the ideal foods. It is not justified to allow the use of certain probiotic organisms, which have long history of safety. It is thus felt that various regulating agencies around the world should review the research data and establish guidelines for assessing probiotic foods for a consistent product all over the world.

\section{Requisites for a probiotic food}

For nutritional and clinical studies on functional foods and probiotic foods for assessing their health claims following information are required [37].

- Every documented strain must be tested independently

- Extrapolation of data from closely related strains should not accepted

- $\quad$ Probiotic strains, study products and study populations must be well-defined

- Double-blind, placebo controlled and randomised human studies must be conducted

- Results obtained must be confirmed by several independent research groups

- Results must be published in peer-reviewed journals

Any probiotic food available in the market must be subjected to the following studies prior to its labeling as "probiotics" [15].

- Genus, species and strains of starter cultures must be identified by phenotypic and genotypic methods

- Functional characterization of the product must be determined through in vitro and animal studies

- Safety assessment of the product must be analyzed through in vitro and animal studies and Phase 1 (Safety) human study

- Double blind, randomized, placebo-controlled (DBPC) Phase 2 (Efficacy) human trial must be carried or through other appropriate design method with sample size and primary outcome appropriate to determine if strain/product is efficacious

- Preferably second independent DBPC study must be done to confirm results

- $\quad$ Phase 3 (Effectiveness) trial is appropriate to compare probiotics with standard treatment of a specific condition

- Phase 4 (Surveillance) trials is necessary for clinical evaluation

- Labeling contents

- Genus, species, strain designation

- Proper storage conditions

- Corporate contact details for consumer information

- Health claims

- The suggested serving size must deliver the effective dose of probiotics related to the health claims

- Minimum numbers of viable bacteria at end of shelf-

life 


\section{Conclusion}

With the realization of the link between the food and health, worldwide consumer's inclination towards healthful foods have increased dramatically in recent years. Due to presence of certain functional properties, probiotics could be exploited as a new promising ingredient for functional food formulations. For successful marketing of probiotics as a functional food, viability of the organisms must be ensured during processing, storage and at the time of consumption. Worldwide regulation and guidelines and a standard of identity must be established to ensure a uniform and safe product.

\section{References}

[1]. Adams CA (2010) The probiotic paradox: live and dead cells are biological response modifiers. Nutr Res Rev 23(1): 37-46.

[2]. Aureli P, Fiore A, Scalfaro C, Casale M, Franciosa G (2010) National survey outcomes on commercial probiotic food supplements in Italy. Int J Food Microbiol 137(2-3): 265-273

[3]. Awad H, Mokhtar H, Imam SS, Gad GI, Hafez H, et al. (2010) Comparison between killed and living probiotic usage versus placebo for the prevention of necrotizing enterocolitis and sepsis in neonates. Pak J Biol Sci 13(6): 253262.

[4]. Besselink MG, van Santvoort HC, Buskens E, Boermeester MA, van Goor $\mathrm{H}$, et al. (2008) Probiotic prophylaxis in predicted severe acute pancreatitis: A Randomised, Double-Blind, Placebo-Controlled Trial. The Lancet 371: 651-659.

[5]. Bezkorovainy, A. (2001), "Probiotics: determinants of survival and growth in the gut”, Am. J. Clin. Nutr., Vol. 73, pp. 399-405.

[6]. Chikindas, M.L. (2014), "Probiotics and antimicrobial peptides: The creatures' and substances' future in the twenty-first century: An opinion letter", Probiotics and Antimicrobial Proteins, Vol. 6, pp. 69-72.

[7]. Collins, M.D. and Gibson G.R. (1999), "Probiotics, prebiotics and synbiotics: dietary approaches for the modulation of microbial ecology", Am. J. Clin. Nutr., Vol. 69, pp.1052-57.

[8]. Conway, P.L., Gorbach, S.L. and Goldin, B.R. (1987), "Survival of lactic acid bacteria in the human stomach and adhesion to intestinal cells", J. Dairy Sci., Vol. 70, pp. 1-12.

[9]. Del Piano, M., Ballare, M., Montino, F., Orsello, M., Garello, F., Ferrari, P., Masini, C., Strozzi, G.P. and Sforza, F. (2004), "Clinical experience with probiotics in the elderly on total enteral nutrition", J. Clin. Gastroenterol., Vol. 38, pp. 111-14.

[10]. Donnet-Hughes, A., Rochat, F., Serrant, P., Aeschlimann, J.M. and Schiffrin, E.J. (1999), "Modulation of nonspecific mechanisms of defense by lactic acid bacteria: effective dose", J. Dairy Sci., Vol. 82, pp. 863-69.

[11]. Doron, S. and Gorbach, S.L. (2006), "Probiotics: their role in the treatment and prevention of disease", Expert Rev. Anti. Infect. Ther., Vol. 4, pp. 261-75.

[12]. Duggan, C., Gannon, J. and Walker, W. A. (2002), "Protective nutrients and functional foods for the gastrointestinal tract", Am. J. Clin. Nutr., Vol. 75, pp. 789-808.

[13]. Ebner, S., Smug, L.N., Kneifel, W., Salminen, S.J. and Sanders, M.E. (2014), "Probiotics in dietary guidelines and clinical recommendations outside the European Union”, World J Gastroenterol, Vol. 20, pp.16095-16100.

[14]. FAO/WHO (2001, "Regulatory and clinical aspects of dairy probiotics", Food and Agriculture Organization of the United Nations, World Health Organization Cordoba, Argentina.

[15]. FAO/WHO (2002), "Guidelines for the Evaluation of Probiotics in Food", Working Group Report on Drafting Guidelines for the Evaluation of Probiotics in Food, London, Ontario, Canada, April 30 and May 1, 2002, Food and Agriculture Organization of the United nations World Health Organization, pp. $1-11$.

[16]. Fijan S. (2014), "microorganisms with claimed probiotic properties: An overview of recent literature", Int. J. Environ. Res. Public Health, Vol.11, pp. 4745-67.

[17]. Grguric, J., Percl, M., Kolacek, S. and Bacic, V. (1996), "Microflora in the digestive tract of infants", Mljekarstvo., Vol. 46, pp. 291-96.

[18]. Hamilton-Miller, J.M., Shah, S. and Winkler, J.T. (1999), "Public health issues arising from microbiological and labelling quality of foods and supplements containing probiotic microorganisms", Public Hlth. Nutr., Vol. 2, pp. 223-29.

[19]. Hill, C., Guarner, F., Reid, G., Gibson, G.R., Merenstein, D.J., Pot, B., Morelli, L., Canani, R.B., Flint, H.J., Salminen, S., Calder, P.C. and Sanders, M.E. (2014), "Expert consensus document. The International Scientific Association for Probiotics and Prebiotics consensus statement on the scope and appropriate use of the term probiotic", Nat. Rev. Gastroenterol. Hepatol., Vol. 11, pp. 506-14.

[20]. Ishibashi, N. and Shimamura, S. 1993), "Bifidobacteria: research and development in Japan”, Fd. Technol., Vol. 47, pp. 126-35.

[21]. Kataria, J., Li, N., Wynn, J.L. and Neu, J. (2009), "Probiotic microbes: do they need to be alive to be beneficial?", Nutr. Rev., Vol. 67, pp. 546-50.

[22]. Kechagia, M., Basoulis, D., Konstantopoulou,S., Dimitriadi, D., Gyftopoulou, K., Skarmoutsou, N. and Fakiri, E.M. (2013), "Health benefits of probiotics: A Review”, ISRN Nutrition, Vol. 2013, Article ID 481651, pp.1-7.

[23]. Kurmann, J.A. and Rasic, J.L. (1991), "The health potential of products containing bifidobacteria", In: Therapeutic properties of fermented milks, Ed. Robinson, R.K., Elsevier Science Publishers Ltd., London, pp. 117-58.

[24]. Liong, M.T. and Shah, N.P. (2005), "Roles of probiotics and prebiotics on cholesterol: The hypothesized mechanisms", Nutrafoods, Vol. 4, pp. 45-57.

[25]. Marteau, P. (2001), "Safety aspects of probiotic products", Scan. J. Nutr., Vol. 45, pp. 22-24.

[26]. Mata, L.J., Carrilo, C. and Villatora, E. (1969), "Fecal microflora in healthy persons in pre-industrial region”, Appl Microbiol., Vol. 17, pp. 596-602.

[27]. Mattila-Sandholm, T., Myllarinen, P., Crittenden, R., Mogensen, G., Fonden, R. and Saarela, M. (2002), "Technological challenges for future probiotic foods", Int. Dairy J., Vol. 12, pp. 173-82.

[28]. McFarland, L.V. and Elmer, G.W. (2006), "Properties of Evidence-Based Probiotics for Human Health”, Ed. Goktepe, I., Juneja, V.K. and Ahmedna, M., Probiotics in Food Safety and Human Health. New York: CRC, pp. 109-37.

[29]. Lourens-Hattingh, A. and Viljoen, B.C. (2001), "Yoghurt as probiotic carrier food", Int. Dairy J., Vol. 11, pp.1-17.

[30]. Payne, J.F., Morris, A.E.J. and Beers, P.J. (1998), "Viability of bifidobacteria in fermented milk products", Functional foods: the consumer, the products and the evidence, Ed. Sadler, M.J. and Saltmarsh, M., pp. 143-48.

[31]. Ram, C. and Chander, H. (2000), "Studies on intestinal microflora of human infants", Indian J. Dairying Biosci., Vol.11, pp. 120-22.

[32]. Reid, G., Jass, J., Sebulsky, M.T. and McCormick, J.K. (2003), "Potential uses of probiotics in clinical practice", Clin. Microbiol. Rev., Vol. 16, pp. 658-72.

[33]. Rijkers, G.T., de Vos, W.M., Brummer, R.J., Morelli, L., Corthier, G. and Marteau, P. (2011), "Health benefits and health claims of probiotics: bridging science and marketing", Br. J. Nutr., Vol. 106, pp. 1291-96

[34]. Ross, R.P., Desmond, C.C., Fitzgerald, G.F. and Stanton, C. (2005), "Overcoming the technological hurdles in the development of probiotic foods", J. Appl. Microbiol., Vol. 98, pp. 1410-17.

[35]. Rotimi, V.O. and Duerden, B. (1981), "The development of the bacterial flora in normal neonates", J. Med. Microbiol., Vol. 14, pp. 51-62.

[36]. Ruemmele, F.M., Bier, D., Marteau, P., Rechkemmer, G., Bourdet-Sicard, R., Walker, W.A. and Goulet, O. (2009), "Clinical evidence for immunomodulatory effects of probiotic bacteria", J. Pediatr. Gastroenterol. Nutr., Vol. 48, pp. 126-41.

[37]. Salminen, S. (2001), "Human studies on probiotics:Aspects of scientific documentation",Scan. J. Nutr., Vol. 45, pp.8-12.

[38]. Salminen, S., Ouwenhand, A., Benno, Y. and Lee, Y.K. (1999), "Probiotics: How should they be defined?", Trends Fd. Sci. Technol., Vol. 10, pp. 107-110.

[39]. Samona, A. and Robinson, R.K. (1994), "Effect of yogurt cultures on the survival of bifidobacteria in fermented milks", J. Soc. Dairy. Technol., Vol. 47, pp. 58-60.

[40]. Sanders, M.E., Tompkins, T., Heimbach, J.T. and Kolida, S. (2004), "Weight of evidence needed to substantiate a health effect for probiotics and prebiotics, regulatory considerations in Canada, E.U. and U.S.:, Eur. J. Nutr., Vol. 44, pp. 303-10.

[41]. Vieira, A.T., Teixeira, M.M. and Martins, F.S. (2013), "The role of probiotics and prebiotics in inducing gut immunity", Front Immunol., Vol. 4, pp. 445.

[42]. Zavisic, Z., Petricevic, S., Radulovic, Z., Begovic, J., Golic, N., Topisirovic, L. and Strahinic, I. (2012), "Probiotic features of two oral lactobacillus isolates”, Braz. J. Microbiol., Vol. 43, pp. 418-28. 